BENTHM OPEN
CrossMark
Content list available at: www.benthamopen.com/TOPSYJ/
DOI: $10.2174 / 1874350101811010089$

RESEARCH ARTICLE

\title{
Residential Satisfaction Among Iranian Senior Citizens
}

\author{
Yadollah Abolfathi Momtaz ${ }^{1,2}$, Bahare Fallahi ${ }^{1, *}$ and Ahmad Delbari ${ }^{1}$ \\ ${ }^{1}$ Iranian Research Center on Aging, University of Social Welfare and Rehabilitation Sciences, Tehran, Iran \\ ${ }^{2}$ Malaysian Research Institute on Ageing (MyAgeing), Universiti Putra Malaysia, Serdang, Selangor, Malaysia
}

Received: April 5, 2018

Revised: April 28, 2018

Accepted: May 2, 2018

\section{Abstract:}

\section{Background:}

The residential satisfaction is one of the major elements of quality of life, particularly in old age.

\section{Objective:}

The aim of this study was to assess residential satisfaction of a sample of Iranian senior citizens in Karaj, Iran.

\section{Methods:}

A cross-sectional design using a convenience sampling technique was employed to obtain a sample of 400 older adults 60 years and over. A validated researcher-constructed questionnaire was used to collect data on residential satisfaction.

\section{Results:}

The mean age of the respondents was $71.82(\mathrm{SD}=7.77)$, with a range from 60 to 98 years. The mean score for residential satisfaction was $130.70(\mathrm{SD}=35.70)$, indicating that the senior citizens were moderately satisfied with the urban space. The safety and security of the residential areas were found to be the most important factors for senior citizens.

\section{Conclusion:}

The findings showed that older adults had moderate satisfaction with residential areas, implying that policymakers should take measures to improve public space. The practical and theoretical implications of the study that may play a critical part in making successful housing policies for aging population are discussed.

Keywords: Aged, Residential satisfaction, Senior citizen, Urban areas, Rural areas, Population.

\section{INTRODUCTION}

The world is experiencing a rapid growth in the number and proportion of older adults. It is projected that there will be 2.03 billion people aged 60 years and over by $2050[1,2]$. The aging population is growing more rapidly in urban areas. According to United Nations, in Asia's urban areas, the growth of people aged 60 years and older from 2000 to 2015 was 106 percent, while over the same period, in rural areas, the number of older persons increased by 28 percent. The faster growth of aging population in urban areas is likely related to differences in mortality risks, which are lower in urban areas compared to rural areas [1].

This rapid growth of the aging population has increased social and economic demands on all countries and raised importance of related issues of quality of life in old age [1]. In order to cope with the rapid ageing population, it is imperative to identify factors that contribute to the quality of life and psychological well-being of older adults [3 - 5].

\footnotetext{
* Address correspondence to this author at the Iranian Research Center on Aging, University of Social Welfare and Rehabilitation Sciences, Tehran, Iran; Tel: +982122180154; E-mail: fallahi.bahare@yahoo.com
} 
One of the major elements of quality of life, particularly in old age, is residential satisfaction [6 - 9]. The quality of life of older adults can be affected by residential conditions through the interior conditions of the home such as bathroom, kitchen, and corridors, and the exterior conditions such as security and illumination [10]. Moreover, older adults with poor residential satisfaction are more likely to be institutionalized [11].

The residential satisfaction can be defined as the fulfillment of the individual residential conditions regarding the needs, expectations and objectives of the inhabitants [6]. It has been also defined as the level of pleasure that people receive from their living place and residents' feeling of satisfaction with their physical living arrangement [7]. In light of the crucial role of residential conditions to the quality of life, several studies have tried to establish significant factors contributing to residential satisfaction. They found that some socioeconomic factors such as age, income, health status, sex, and level of education are associated with residential satisfaction [7, 12, 13]. One of the most important theories that would best complement the current research is the theory of Person-Environment (P-E) Fit. The P-E fit theory has been defined as the degree to which residents and environmental conditions match [13]. It presumes that the suitability of a living space in old age depends on mutual adaptation between older adults' needs and environmental conditions. According to P-E fit theory, residential satisfaction can be influenced by accessibility, the subjective sense of usability, and the extent to which material conditions meet personal needs of residents. Furthermore, residential satisfaction can be affected by residents' sociodemographic characteristics, accessibility of services, amenities, inter-personal relationships, and health status of the residents [14].

Traditionally, in Iran, a country in southwest Asia, houses were designed based on careful attention to climatic requirements in social-cultural context to provide physical and mental comforts to residents [15]. The culture and religious values have forced Iranians to have a suitable dwelling. The security and peace are two important factors that affect housing forms with limited openings and view to outside [16].

As mentioned above, the fast growth of aging population in urban areas and crucial role of residential conditions on quality of life in old age, the present study was conducted to assess residential satisfaction of older adults 60 years and over in Karaj, Iran. Karaj as the fourth-largest city in Iran is the capital of Karaj County, Alborz Province. In the 2011 census, its population was $1,979,249$. It is surrounded by mountains which give it great landscapes.

\section{RESEARCH METHOD}

This cross-sectional study was conducted from December 2016 to February 2017 in Karaj, Iran. A convenience sampling method was employed to select a sample of 400 senior citizens, aged 60 years or over, from public places such as parks, shops, and libraries. The data were collected using a questionnaire by one trained enumerator.

The survey questionnaire included two parts. The first section assessed sociodemographic characteristics of the senior citizens including age, sex, marital status, level of education, and employment status. The second part of the questionnaire measured residential satisfaction using a validated researcher-constructed questionnaire, consisting of 38 items rated on a five-point Likert scale ranging from 1 as very dissatisfied to 5 as very satisfied. With regards to the fact that residential area includes the home and the environment where it is located and people are living [17], in this study, residential satisfaction included both the space and people. This study assessed the residential satisfaction which contains 8 components: (1) Neighborhood facilities with 10 items; (2) Comfort with 8 items; (3) Safety and security with 4 items; (4) Citizen participation with 3 items; (5) Vitality with 3 items; (6) Legibility with 2 items; (7) Control and monitoring with 4 items; and Cultural facilities with 4 items.

The residential satisfaction questionnaire was developed based on the theoretical framework and literature review [17]. The content validity of the questionnaire was assessed using the Content Validity Index (CVI) based on experts' ratings of item relevance. The CVI assesses the relevancy of an item to the respective construct [18]. The mean score for CVI was found to be 0.90 , indicating appropriate content validity for residential satisfaction questionnaire.

The reliability of the residential satisfaction questionnaire and its subscales using Cronbach's alpha coefficient ranged from .70 to .94 , which indicated good internal consistency.

\section{STATISTICAL ANALYSIS}

The descriptive and inferential statistics using IBM SPSS version 22 were used to fulfill study purpose. Univariate and bivariate analyses were performed to assess variables distribution and identify potential statistical associations between independent and dependent variables. A two-tailed $\alpha$ value of 0.05 was considered as the level of statistical significance. 


\section{RESULTS}

A total of 400 community-dwelling elderly people were interviewed. One questionnaire was excluded from the analysis because of incomplete response. The age range was 60 to 98 years and the mean age was $71.82(\mathrm{SD}=7.77)$. The sex distribution of the respondents was almost similar to overall trends in aging population, with $53.1 \%$ male and $46.9 \%$ female. Table 1 presents the sociodemographic characteristics of the respondents.

Table 1. The sociodemographic characteristics of the respondents.

\begin{tabular}{|c|c|c|c|}
\hline \multicolumn{2}{|c|}{ Variable } & $\mathbf{n}$ & $\mathbf{\%}$ \\
\hline \multirow{3}{*}{ Sex } & Male & 212 & 53.1 \\
\cline { 2 - 4 } & Female & 187 & 46.9 \\
\hline \multirow{4}{*}{ Marital status } & Never Married & 20 & 5.0 \\
\cline { 2 - 4 } & Married & 271 & 67.9 \\
\cline { 2 - 4 } & Divorced / Separated & 21 & 5.3 \\
\cline { 2 - 4 } & Widowhood & 87 & 21.8 \\
\hline \multirow{3}{*}{ Education } & No formal education & 284 & 71.2 \\
\cline { 2 - 4 } & Secondary School & 72 & 18.0 \\
\cline { 2 - 4 } & Diploma & 27 & 6.8 \\
\cline { 2 - 4 } & Bachelor & 12 & 3.0 \\
\cline { 2 - 4 } & Master & 4 & 1.0 \\
\hline \multirow{3}{*}{ Employment status } & Unemployed & 19 & 4.8 \\
\cline { 2 - 4 } & Retired & 209 & 52.4 \\
\cline { 2 - 4 } & Employed & 171 & 42.9 \\
\hline
\end{tabular}

Families with two members were dominant (25.6\%), three member families $(24.10 \%)$, and $18 \%$ of the participants had secondary school education. In terms of employment status, $52.4 \%$ of the respondents were retired.

\section{RESIDENTIAL SATISFACTION}

The mean score for residential satisfaction was $130.70(\mathrm{SD}=35.70)$, indicating that the senior citizens were moderately satisfied with the urban space. Results of a series of independent $t$-tests revealed no significant differences between male $(\mathrm{M}=131.57, \mathrm{SD}=20.78)$ and female $(\mathrm{M}=129.73, \mathrm{SD}=21.18)$, employed $(\mathrm{M}=132.31, \mathrm{SD}=17.21)$ and unemployed $(\mathrm{M}=129.50, \mathrm{SD}=23.35)$, highly educated $(\mathrm{M}=135.56, \mathrm{SD}=23.97)$ and low educated $(\mathrm{M}=130.12, \mathrm{SD}=$ 20.53), married $(\mathrm{M}=130.69, \mathrm{SD}=19.5)$ and unmarried $(\mathrm{M}=130.73, \mathrm{SD}=23.80)$ respondents.

The mean satisfaction scores of older adults with components of urban space have been presented in Table $\mathbf{2}$. To compare mean subscale scores, each of the raw subscale scores was divided by the number of items in each subscale. As can be seen from Table 2, the scores are ranked and sorted from highest to lowest means. Safety and security received highest satisfaction. By contrast, control and monitoring component received lowest satisfaction.

Table 2. The mean satisfaction scores with components of urban space.

\begin{tabular}{|c|c|c|c|}
\hline Components & Items & Mean & SD \\
\hline Safety and security & 4 & 14.89 & 3.12 \\
\hline Comfort & 8 & 29.18 & 5.6 \\
\hline Social participation & 3 & 10.93 & 2.34 \\
\hline Vitality & 3 & 10.51 & 2.58 \\
\hline Neighborhood facilities & 10 & 34.22 & 4.19 \\
\hline Legibility & 2 & 6.51 & 1.89 \\
\hline Cultural facilities & 4 & 9.12 & 4.34 \\
\hline Control and monitoring & 4 & 8.05 & 3.29 \\
\hline
\end{tabular}

In order to categorize residential satisfaction into three levels, range of the scale was calculated. To obtain the range of residential satisfaction scale, the minimum possible score was subtracted from the maximum possible score. Then, the computed range of the scale was divided by three, which yielded the range value between the three levels (Low, Moderate, High). Finally, as shown in Table 3, lower and higher bounds for each level were calculated. As presented in Table 3, majority of the senior residents (64.7\%) had moderate residential satisfaction. 
Table 3. The results of categorizing residential satisfaction.

\begin{tabular}{|c|c|c|c|c|}
\hline Level & Lower Bound & Higher Bound & n & 6 \\
\hline Low & 38 & 88.6 & 1.5 & 6 \\
\hline Moderate & 88.7 & 139.2 & 258 & 64.7 \\
\hline High & 139.3 & 190 & 135 & 33.8 \\
\hline
\end{tabular}

\section{DISCUSSION}

As the populations of cities have been aging rapidly over the recent decades, the issues of older people are increasingly becoming a significant topic in urban research and a relevant challenge for planning and managing neighborhoods and communities in cities. Therefore, providing essential services for older people living in urban areas is crucial to support their daily life in urban areas. Residential satisfaction is a subjective evaluation of the extent to which residential needs of people are fulfilled [19].

The current study was conducted to assess urban public satisfaction among older adults in the city of Karaj, Iran. The results revealed that elderly citizens had moderate satisfaction with urban public satisfaction. This finding was consistent with the results from a study in Prague that showed that elderly people were fairly satisfied with their residential environment in terms of accessibility to services, public spaces, housing and social support [19]. However, descriptive results from a representative sample of community-dwelling older adults aged 65 to 84 years in Madrid (Spain) showed a high degree of satisfaction with the residential environment [17]. It is worth mentioning that residential satisfaction varied from place to place and is significantly influenced by social-cultural values [20].

The results revealed that the safety and security of the residential condition were found to be the most important factors for senior citizens. This finding is consistent with previous investigations [21 - 24] demonstrating that safety is one of the most important factors contributing to residential satisfaction. In addition, Lovejoy, Handy [25], Bjorklund and Klingborg [26], and Parkes, Kearns [27] in their studies found that perception of safety was the most important contributing factor to residential satisfaction. The findings from the present study support the P-E fit theory, in which safety is an important determinant of residential satisfaction in general population and particularly in the elderly [14, $20]$.

Although some previous studies found that socioeconomic and demographic variables are significant predictors of residential satisfaction for elderly [22, 28, 29], the current study did not find a statistically significant relationship between sociodemographic factors and residential satisfaction.

It is noteworthy to mention that in our study male, highly educated, married, and employed senior citizens had higher level of residential satisfaction compared to their female, low educated, unmarried, and unemployed counterparts. The lack of sociodemographic differences in residential satisfaction among senior citizens in the present study, should not be interpreted as the absence of any relationship between sociodemographic factors and residential satisfaction. In any study, non-significant findings can occur for several reasons, such as small and homogeneous sample. The small sample size can influence the statistical results [30,31]. Non-probability sample coupled with the homogeneous sample may also produce non-significant results.

Like any other studies, the current study is not free of limitations. It has some limitations that should be addressed and considered in future studies. First, due to cross-sectional nature of the study, it is difficult to make a firm conclusion about the findings. The second limitation is related to sampling method. As this study employed a convenience sampling method, the findings have a limited generalizability. The last limitation that should be noted is related to the educational level of the respondents. As the majority of the sample had no formal education, it is challenging to compare the finding from the present study with previous studies.

With regard to the fact that security and peace are culturally two important influencing factors for housing forms [16] and the results of this study showed that safety and security of the residential condition are most important factors for senior citizens, the government should consider the concerns of the aged population in developing cities that meet older adults' needs. Additionally, housing developers should consider social-cultural values of the elderly to fulfill appropriate designs that contribute to increased residential satisfaction.

\section{ETHICS APPROVAL AND CONSENT TO PARTICIPATE}

The study was approved by the University of Social Welfare and Rehabilitation Sciences, Tehran, Iran. 


\section{HUMAN AND ANIMAL RIGHTS}

No Animals were used in this research. All human research procedures followed were in accordance with the ethical standards of the committee responsible for human experimentation (institutional and national), and with the Helsinki Declaration of 1975, as revised in 2013.

\section{CONSENT FOR PUBLICATION}

Before commencing the interview, oral informed consent was obtained from all participants

\section{CONFLICT OF INTEREST}

The authors declare no conflict of interest, financial or otherwise.

\section{ACKNOWLEDGEMENTS}

This study was supported by grant No 9352 in University of Social Welfare \& Rehabilitation Sciences. The authors are grateful to the study participants, editor, and anonymous reviewers.

\section{REFERENCES}

[1] United Nations. Department of Economic and Social Affairs, Population Division. World Population Ageing 2015 (ST/ESA/SER.A/390), 2015.

[2] Hamid TA, Momtaz YA, Abdul Rashid. S.N.S. (2010). Older women and lower self-rated health.Educ Gerontol 2010; 36(6): 521-8. [http://dx.doi.org/10.1080/03601270903534606]

[3] Ibrahim R, Momtaz YA, Hamid TA. Social isolation in older Malaysians: Prevalence and risk factors. Psychogeriatrics 2013; $13(2)$ : 71-9. [http://dx.doi.org/10.1111/psyg.12000] [PMID: 23909963]

[4] Yahaya N, Suhailah S. A, Abolfathi M. Y. Quality of life of older malaysians living alone. Educ Gerontol 2010; 36(10): 893-906. [http://dx.doi.org/10.1080/03601271003609009]

[5] Momtaz YA, Hamid TA, Yahaya N. The role of religiosity on relationship between chronic health problems and psychological well-being among Malay Muslim older persons. Res J Med Sci 2009; 3(6): 188-93.

[6] Fernandez-Portero C, Alarcón D, Barrios Padura Á. Dwelling conditions and life satisfaction of older people through residential satisfaction. J Environ Psychol 2017; 49: 1-7. [http://dx.doi.org/10.1016/j.jenvp.2016.11.003]

[7] Ahn M, Lee S-J. Housing satisfaction of older (55+) single-person householders in US rural communities. J Appl Gerontol 2016; 35(8): $878-911$.

[http://dx.doi.org/10.1177/0733464815577142] [PMID: 25846383]

[8] Smith KM. The relationship between residential satisfaction, sense of community, sense of belonging and sense of place in a western Australian urban planned community.2011.

[9] Mccrea R, R. Stimson, J. Western. Testing a moderated model of satisfaction with urban living using data for Brisbane-South East Queensland, Australia. Social indicators research,2005; 72(2): 121-52.

[http://dx.doi.org/10.1007/s11205-004-2211-x]

[10] Phillips DR, Siu OL, Yeh AG, Cheng KH. The impacts of dwelling conditions on older persons' psychological well-being in Hong Kong: the mediating role of residential satisfaction. Soc Sci Med 2005; 60(12): 2785-97. [http://dx.doi.org/10.1016/j.socscimed.2004.11.027] [PMID: 15820587]

[11] Perez FR, Fernandez-Mayoralas Gloria, Enrique Pozo Rivera F, Abuin JMR. Ageing in place: Predictors of the residential satisfaction of elderly. Soc Indic Res 2001; 54(2): 173-208.

[http://dx.doi.org/10.1023/A:1010852607362]

[12] Lee S-j, Parrott KR. Housing satisfaction of Asian and pacific Island elders in the United States. Hous and Soci 2010; 37(2): 185-205. [http://dx.doi.org/10.1080/08882746.2010.11430586]

[13] Kahana E, Lovegreen L, Kahana B. Person, environment, and person-environment fit as influences on residential satisfaction of elders. Environ Behav 2003; 35(3): 434-53.

[http://dx.doi.org/10.1177/0013916503035003007]

[14] Fernández-Carro C, Módenes JA, Spijker J. Living conditions as predictor of elderly residential satisfaction. A cross-European view by poverty status. Eur J Ageing 2015; 12(3): 187-202. [http://dx.doi.org/10.1007/s10433-015-0338-z] [PMID: 28804354]

[15] Soflaei F, Shokouhian M, Zhu W. Socio-environmental sustainability in traditional courtyard houses of Iran and China. Renew Sustain Energy Rev 2017; 69: 1147-69.

[http://dx.doi.org/10.1016/j.rser.2016.09.130] 
[16] Shabani M. M, Tahir M. M, Shabankareh H, Arjmandi H, Mazaheri F. Relation of cultural and social attributes in dwelling, responding to privacy in Iranian traditional house. e-BANGI, 2011. 6(2): p. 273.

[17] Cramm JM, Nieboer AP. Relationships between frailty, neighborhood security, social cohesion and sense of belonging among community $\square$ dwelling older people. Geriatr \& gerontol int. 2013 Jul 1;13(3):759-63. [http://dx.doi.org/10.1111/j.1447-0594.2012.00967.x]

[18] Polit D, Beck T, Owen S. Focus on research methods is the CVI an acceptable indicator of content validity. Res Nurs Health 2007; 30: 459-67. [http://dx.doi.org/10.1002/nur.20199] [PMID: 17654487]

[19] Temelova J, Dvorakova N. Residential satisfaction of elderly in the city centre: The case of revitalizing neighbourhoods in Prague. Cities 2012; 29(5): 310-7.

[http://dx.doi.org/10.1016/j.cities.2011.11.015]

[20] Mohit MA, Raja AMMA-K. Residential satisfaction: Concept, theories and empirical studies. Plan Malaysia 2014; $12(3)$ : 47-66.

[21] Le Roux N. Homeowners' experience of the reality of homeownership in upmarket security estates in Tshwane, South Africa. 2011.

[22] Deal RL. Residential satisfaction of the elderly: Does perceived neighborhood safety matter. 2012.

[23] Ståhl A, Carlsson G, Hovbrandt P, Iwarsson S. "Let's go for a walk!": Identification and prioritisation of accessibility and safety measures involving elderly people in a residential area. Eur J Ageing 2008; 5(3): 265-73.

[http://dx.doi.org/10.1007/s10433-008-0091-7] [PMID: 28798578]

[24] Aigbavboa C. Assessing beneficiaries' needs and expectations as a determinant of residential satisfaction in South Africa. Hous Sup 2016; 19(1): 10-22. [http://dx.doi.org/10.1108/HCS-01-2016-0001]

[25] Lovejoy K, Handy S, Mokhtarian P. Neighborhood satisfaction in suburban versus traditional environments: An evaluation of contributing characteristics in eight California neighborhoods. Landsc Urban Plan 2010; 97(1): 37-48. [http://dx.doi.org/10.1016/j.landurbplan.2010.04.010]

[26] Bjorklund K, Klingborg K. Correlation between negotiated rents and neighbourhood quality: A case study of two cities in Sweden. Housing Stud 2005; 20(4): 627-47. [http://dx.doi.org/10.1080/02673030500114623]

[27] Parkes A, Kearns A, Atkinson R. The Determinants of Neighborhood Dissatisfaction. Bristol, UK: Economic \& Social Research Council Centre for Neighbourhood Research 2002.

[28] Phillips D. R, Siu O. L, Anthony G.O. Y, Cheng H.C. K. Factors influencing older persons' residential satisfaction in big and densely populated cities in asia: A case study in Hong Kong. Ageing Int 2004; 29(1): 46-70. [http://dx.doi.org/10.1007/s12126-004-1009-0]

[29] Rioux L, Werner C. Residential satisfaction among aging people living in place. J Environ Psychol 2011; 31(2): 158-69. [http://dx.doi.org/10.1016/j.jenvp.2010.12.001]

[30] Quertemont E. How to statistically show the absence of an effect. Psychol Belg 2011; 51(2): 109-27. [http://dx.doi.org/10.5334/pb-51-2-109]

[31] Batterham AM, Hopkins WG. Making meaningful inferences about magnitudes. Int J Sports Physiol Perform 2006; 1(1): 50-7. [http://dx.doi.org/10.1123/ijspp.1.1.50] [PMID: 19114737]

This is an open access article distributed under the terms of the Creative Commons Attribution 4.0 International Public License (CC-BY 4.0), a copy of which is available at: (https://creativecommons.org/licenses/by/4.0/legalcode). This license permits unrestricted use, distribution, and reproduction in any medium, provided the original author and source are credited. 